NBER WORKING PAPER SERIES

\title{
WHEN CAN CHANGES IN EXPECTATIONS CAUSE BUSINESS CYCLE FLUCTUATIONS IN NEO-CLASSICAL SETTINGS?
}

\author{
Paul Beaudry \\ Franck Portier \\ Working Paper 10776 \\ http://www.nber.org/papers/w10776
NATIONAL BUREAU OF ECONOMIC RESEARCH
1050 Massachusetts Avenue
Cambridge, MA 02138
September 2004

The authors thank Alain Venditti, Harald Uhlig and participants at seminars at GREQAM and EUREQUA and Florence 2004 SED meeting for helpful comments. The views expressed herein are those of the author(s) and not necessarily those of the National Bureau of Economic Research.

(C2004 by Paul Beaudry and Franck Portier. All rights reserved. Short sections of text, not to exceed two paragraphs, may be quoted without explicit permission provided that full credit, including $\odot$ notice, is given to the source. 
When Can Changes in Expectations Cause Business Cycle Fluctuation in Neo-Classical Settings? Paul Beaudry and Franck Portier

NBER Working Paper No. 10776

September 2004

JEL No. E3

\begin{abstract}
It is often argued that changes in expectation are an important driving force of the business cycle. However, it is well known that changes in expectations cannot generate positive co-movement between consumption, investment and employment in the most standard neo-classical business cycle models. This gives rise to the question of whether changes in expectation can cause business cycle fluctuations in neo-classical setting or whether such a phenomenon is inherently related to market imperfections. This paper offers a systematic exploration of this issue. Our finding is that expectation driven business cycle fluctuation can arise in neo-classical models when one allows for a sufficient rich description of the inter-sectorial production technology, however such a structure is rarely allowed in macro-models. In particular, the key characteristic which we isolate as giving rise to the possibility of Expectation Driven Business Cycles is that intermediate good producers exhibit cost complementarities (i.e., economies of scope) when supplying intermediate goods to different sectors of the economy.

Paul Beaudry

Department of Economics

University of British Columbia

997-1873 East Mall

Vancouver, B.C.

CANADA V6T 1Z1

and NBER

paulbe@interchange.ubc.ca

Franck Portier

Manufacture des Tabacs

Universite des Sciences de Toulouse

21 allee de Brienne

31000 Toulouse

FRANCE

fportier@cict.fr
\end{abstract}




\section{Introduction}

A common perception among economic observers is that macroeconomic fluctuations are not driven

only by current developments in the economy but are often influenced by perceptions of future developments, that is, they may be driven by changes in expectations as opposed to current changes in opportunities or preferences. In effect, to most business economists, this is an undisputable fact. The 1999-2001 boom-bust cycle in the US is one example which may fit this idea. For many, the 1999-2001 period was one where agents' rosy expectations of the future contributed significantly to the high growth rates of 1999 and 2000, while a revision of these expectations caused the downturn of 2001. Similar stories are given for the booms and busts observed in the late 1990s in Asia. In a systematic way, Beaudry and Portier [2004b] show that, using U.S. postwar data, stock prices movements predict TFP growth, and that such stock price booms are accompanied by an overall macroeconomic expansion. Given the plausibility that at least some business cycle episodes are driven by expectations (which may be thought as a type of demand disturbance), it is relevant to circumscribe the classes of models which are capable of generating such phenomena. Knowing whether a model has such a characteristic may be a useful element to evaluate its plausibility.

The object of this paper is to examine whether, and if so under what conditions, Expectation Driven Business Cycles can arise in simple neo-classical settings. That is, we will examine whether expectations alone could cause booms or busts - defined as positive co-movement in consumption, investment and employment- in a setting with constant returns to scale technology and perfect markets. We are interested in examining this question within a constant returns to scale and perfect market setting for three reasons. First, a substantial body of empirical literature (see Burnside, Eichenbaum, and Rebelo [1995], Basu [1996] and Basu and Fernald [1997]) supports the assumption of constant returns to scale. Second, perfect competition appears to us as the good benchmark to begin a systematic exploration of this issue. In particular, by adopting this focus we can learn whether or not Expectation Driven Business Cycles are inherently related to market imperfections or whether they can arise in perfect market setting. Third, it is well known in the 
literature that the simplest one-sector neo-classical model is incapable of supporting expectation driven booms and bust since, in the absence of a current change in technology, consumption and employment on the one side and consumption and investment on the other side, always exhibit negative co-movement 11 Hence, part of our aim is to understand the generality of this observation.

In order to favor tractability and transparency, we limit our analysis to neo-classical models where the capital stock is the only state variable (this is what we mean by the term simple neoclassical models). One of the attractive features of a one state variable setting is that its dynamics can be represented on a two dimensional phase diagram and therefore can be easily compared with well known results in the literature.

The two main results of the paper are: (1) Expectation Driven Business Cycles are possible in simple neo-classical settings, that is, we show that strictly positive co-movement between consumption, investment and employment can arise in simple perfect market settings as the result of changes in expectation; and (2) most commonly used macro models restrict the production possibility set in a manner that precisely rules out the possibility of Expectation Driven Business Cycles in the presence of market clearing. The main technological features we identify as being intimately linked with the possibility of Expectation Driven Business Cycles is that of a multi-sector setting where firms exhibit a type of economy of scope. However, most commonly used macro models do not allow for rich inter-sectorial production technologies, or if they do, they impose linear production possibility frontiers which rule out any economies of scope. Therefore these models can not support expectation driven booms and busts; instead in these models expectational change always lead to negative co-movement between consumption and investment. Hence, our results suggest that Expectation Driven Business Cycles can be explained in a perfect market explanation if one is ready to entertain the possibility of firms with economies of scope or, in other words, internal cost complementarities between the production of different goods. Let us stress the necessary technological structure is not very exotic, nor absent from the literature, as it is implicitly implied by models which adopt

\footnotetext{
${ }^{1}$ Such a consumption-investment correlation pattern can also be found in response to a sunspot shock, as discussed in Benhabib and Farmer [1996].
} 
multi-sectorial investment adjustment costs as in Sims [1989], Vallés [1997], Huffman and Wynne [1999] and Kim [2003]) ${ }^{2}$ Whether or not real economies exhibit the cost structure needed to support the type of expectational driven fluctuations examined here remains an empirical issue, which we leave for future research. However, we believe that our analysis nicely isolates technological features which helps explain what is often coined as Keynesian type phenomena, that is Expectation Driven Business Cycles, without the need to invoke market imperfections.

Before outlining the structure of the paper, let us first clarify that the aim of our analysis is not to identify whether Expectation Driven Business Cycles are the result of rational or irrational forecasts. Our aim is to examine whether Expectation Driven Business Cycles can arise when all current spot markets are required to be in equilibrium. In the main part of our analysis, we will not need to specify whether the the underlying change in expectation is the result of a properly forecasted change in future fundamentals or whether it is based on foolish perceptions. Instead we adopt a temporary equilibrium approach which allows us to directly focus on whether positive co-movements between consumption, investment and employment can arise as the result of some expectational change, whether it be rational or irrational. In order to understand our approach, it is useful to consider the phase diagram associated with a standard one sector neo-classical model as presented in Figure 1. On this figure, we have traced the stable saddle path as well as some of the unstable paths. It is well known that starting from an initial steady state, an anticipated change in a fundamental will cause the economy to jump and evolve along one of the unstable paths until the anticipated change is realized. The nature of the dynamics in this case implies that a jump due to an anticipated change in fundamentals will always involve a negative co-movement between consumption and investment. Specifically, such a jump will either cause an increase in consumption and a decrease in investment or the converse, regardless of the source of the expectational change.

\footnotetext{
${ }^{2}$ Kim [2003] shows that, in the absence of variable labor supply, multi-sectorial investment costs are observationaly equivalent to intertemporal investment costs. However, as we will show, this equivalence does not hold with variable labor supply. In particular, intertemporal adjustment costs model cannot support positive co-movement between consumption, investment and employment due to changes in expectations, while models with multi-sector investment costs can.
} 
Hence, the issue we want to explore is whether simple neo-classical models inherently imply a dynamic structure in which an expectational changes always lead to negative co-movement between consumption and investment; or alternatively, if it is possible for neo-classical models to exhibit the dynamic structure depicted in Figure 2. In particular, in Figure 2 we have illustrated a dynamic system which is saddle path stable and which has the property that a jump from the steady state to an unstable path always involves a positive co-movement between consumption and investment. Therefore, our main question can be stated as examining the conditions under which (if any) a neo-classical model can generate a dynamic system similar to that depicted in Figure 2.

The remaining sections of the paper are as follows. In section 2, we present the class of economies to be considered, and define our notion of Expectation Driven Business Cycles. In section 3, we examine several standard macroeconomic models to see whether they can possibly support Expectation Driven Business Cycles. The models examined include standard one and two-sector models, models with adjustment cost and models with variable capacity utilization. In section 4 , we examine multi-sector models and show that Expectation Driven Business Cycles can arise in such settings if there are multi-product firms which supply intermediate goods to both the consumption and investment sectors, and exhibit some cost complementarity in doing so. We also relate the technological restrictions we have derived with the nature of the economy's phase diagram in the consumption-capital space. Finally, in section 5 we present a fully specified example where Expectation Driven Business Cycles arise under rational expectations. Section 6 offers concluding comments.

\section{Structure}

Here we present the economic environment and define the main concepts we use. Assumptions made for preferences and technology are standard. The only difference is in the notations we use for technology, that allows to treat comprehensively different production structures. Given those fundamentals, we define competitive allocations and Expectation Driven Business Cycles. 


\subsection{Preferences and Technology}

Let us consider an environment with a representative agent whose preferences over consumption and leisure are ordered by

$$
E_{0} \sum_{t=0}^{\infty} \beta^{t} U\left(C_{t}, 1-L t\right),
$$

where $U(\cdot, \cdot)$ is a twice continuously differentiable and quasi-concave function, $C_{t}$ is consumption, $1-L_{t}$ is leisure time (i.e. $L_{t}$ is labor supply) with total per-period time endowment normalized to 1 , and $\beta \in] 0,1[$. The one additional assumption we place on the utility function it that consumption and leisure are normal goods. More precisely, it is assumed that $U_{1}>0, U_{2}>0,-U_{11} / U_{1}>U_{12} / U_{2}$ and $-U_{22} / U_{2}>U_{12} / U_{1}$.

At a point in time $t$, the production opportunities available in the economy are assumed to be represented by

$$
C_{t}=G\left(K_{t}, L_{t}, I_{t} ; \psi_{t}\right)
$$

Here $K_{t}$ denotes the capital stock, $I_{t}$ is the level of investment in capital and $\psi_{t}$ represents the state of technology. For a given $\psi_{t}$, we assume that the function $G$ is homogenous of degree one, that $G_{K_{t}}>0, G_{L_{t}}>0, G_{I_{t}}<0$ and that the set $\left\{C_{t}, K_{t}, L_{t}, I_{t}\right\}$ defined by $C_{t}-G\left(K_{t}, L_{t}, I_{t}\right) \leq 0$ is convex.

We further assume that capital is accumulated over time according to

$$
K_{t+1}=I_{t}+(1-\delta) K_{t}
$$

where $\delta \in[0,1]$ is the rate of depreciation. Later on we will allow for more general forms of accumulation.

Remark : Our formulation of the technological opportunities encompasses many of the those used in the macro literature. For example, it encompasses the standard one-sector model since in this case the function $G(\cdot)$ can be written as

$$
G\left(K_{t}, L_{t}, I_{t} ; \psi_{t}\right)=F\left(K_{t}, L_{t} ; \psi_{t}\right)-I_{t}
$$


where $F(\cdot)$ is the one-sector concave production function. One-sector models with convex capital adjustment cost are also encompassed, since in this case the function $G(\cdot)$ can be written as

$$
G\left(K_{t}, L_{t}, I_{t} ; \psi_{t}\right)=F\left(K_{t}, L_{t} ; \psi_{t}\right)-I_{t}-\phi\left(\frac{I_{t}}{K_{t}}\right)
$$

where $F(\cdot)$ is the one-sector concave production function and $\phi(\cdot)$ is a convex cost of adjustment function.

This formulation also encompasses standard two-sector model since the function $G(\cdot)$ can be seen as a value function defined by

$$
\begin{array}{r}
G\left(K_{t}, L_{t}, I_{t}\right)=\max _{K_{t}^{C}, K_{t}^{I}, L_{t}^{C}, L_{t}^{I}} F^{C}\left(K_{t}^{C}, L_{t}^{C}\right) \\
\text { s.t. }\left\{\begin{array}{l}
F^{I}\left(K_{t}^{I}, L_{t}^{I}\right) \geq I_{t} \\
K_{t}^{C}+K_{t}^{I} \leq K_{t} \\
L_{t}^{C}+L_{t}^{I} \leq L_{t}
\end{array}\right.
\end{array}
$$

where $F^{C}\left(K^{C}, L^{C}\right)$ is the production function for consumption goods and $F^{I}\left(K^{I}, L^{I}\right)$ for investment goods.

\subsection{Equilibrium Allocations}

We consider a structure in which firms are owned by households. Since the Walrasian equilibrium for this economy is efficient, equilibrium quantities of consumption, employment, capital and investment are solutions of the following social planner problem:

$$
\begin{aligned}
& \max _{C_{t}, I_{t}, L_{t}, K_{t+1}} E_{0} \sum_{t=0}^{\infty} \beta^{t} U\left(C_{t}, 1-L t\right) \\
& \text { s.t. }\left\{\begin{array}{l}
C_{t} \leq G\left(K_{t}, L_{t}, I_{t} ; \psi_{t}\right) \\
K_{t+1} \leq I_{t}+(1-\delta) K_{t}
\end{array}\right.
\end{aligned}
$$

and therefore need to solve

$$
\begin{aligned}
U_{2}\left(C_{t}, 1-L_{t}\right) & =U_{1}\left(C_{t}, 1-L_{t}\right) G_{L}\left(K_{t}, L_{t}, I_{t} ; \psi_{t}\right) \\
C_{t} & =G\left(K_{t}, L_{t}, I_{t} ; \psi_{t}\right) \\
U_{1}\left(C_{t}, 1-L_{t}\right) & =\beta E_{t}\left[U _ { 1 } ( C _ { t + 1 } , 1 - L _ { t + 1 } ) \left(\frac{G_{K}\left(K_{t+1}, L_{t+1}, I_{t+1} ; \psi_{t+1}\right)}{G_{I}\left(K_{t}, L_{t}, I_{t} ; \psi_{t}\right)}\right.\right.
\end{aligned}
$$




$$
\begin{aligned}
& \left.\left.+(1-\delta) \frac{G_{I}\left(K_{t+1}, L_{t+1}, I_{t+1} ; \psi_{t+1}\right)}{-G_{I}\left(K_{t}, L_{t}, I_{t} ; \psi_{t}\right)}\right)\right] \\
K_{t+1}= & I_{t}+(1-\delta) K_{t} .
\end{aligned}
$$

Equation (4) describes the intratemporal choice between consumption and leisure and equation (6) describes the intertemporal choice between consumption today and consumption tomorrow. The two other equations are simply the resource constraint in period $t$ and the accumulation equation.

\subsection{Expectation Driven Business Cycles}

The question we now want to examine is under what conditions can changes in expectations lead to positive co-movement between consumption, investment and employment, holding current technology, $\psi_{t}$, and preferences fixed. We will refer to such phenomena as Expectation Driven Business Cycles, as made explicit in the definition below. To answer this question it is useful to focus on the two equations (4) and (5). These two equations can be seen as defining combinations of consumption, investment and employment which are consistent with period $t$ market clearing in both the goods market and the labor market. In other words, the equations (4) and (5) define a surface which represents the set of all possible temporary equilibrium quantities (or the set of current equilibrium quantity combinations that can arise for some expectation about the future). Hence, if changes in expectations are to lead to positive co-movement between consumption, investment and employment, then it must be the case that the surface defined by equations (4) and (5) has the property that $\frac{\partial c}{\partial I}>0$ and $\frac{\partial L}{\partial I}>0$. This leads us to the following statement.

Definition 1 Expectation Driven Business Cycles represents a positive co-movement between consumption, investment and employment induced by a change in expectations holding current technology, preferences and government interventions constant.

In Appendix A, we provide another formulation of this definition that make more explicit what we mean by a change in expectations. Given this definition, the following statement immediately follows: 
Lemma 1 Expectation Driven Business Cycles can arise in a Walrasian equilibrium only if the surface defined by equations (4) and (5) has the property that $\frac{\partial C}{\partial I}>0$ and $\frac{\partial L}{\partial I}>0$

The main objective of the following two sections will be to examine different production structures and preferences to see whether Expectation Driven Business Cycles could potentially arise in these environments ${ }^{3}$ In particular, this will allow us to highlight the role of multi-product firms in allowing for Expectation Driven Fluctuations.

\subsection{A More General Structure}

It is useful for future reference to have defined a slightly more general production structure in which we combine the accumulation equation (3) and the current production possibilities (2) is as follows.

$$
C_{t}=\widetilde{G}\left(K_{t}, L_{t}, K_{t+1} ; \psi_{t}\right)
$$

where $\widetilde{G}$ is homogenous of degree one, $\widetilde{G}_{K_{t}}>0, \widetilde{G}_{L_{t}}>0, \widetilde{G}_{K_{t+1}}<0$ and the set $\left\{C_{t}, K_{t}, L_{t}, K_{t+1}\right\}$ defined by $C_{t}-\widetilde{G}\left(K_{t}, X_{t} L_{t}, K_{t+1}\right) \leq 0$ is convex ${ }^{4}$

Obviously, this formulation encompasses our previous formulation since in such a case $\widetilde{G}\left(K_{t}, L_{t}, K_{t+1} ; \psi_{t}\right)$ can be defined as $G\left(K_{t}, L_{t}, K_{t+1}-(1-\delta) K_{t} ; \psi_{t}\right)$. The advantage of this second formulation is that it can encompass models with variable capacity utilization, since $\widetilde{G}(\cdot)$ can be seen as the value function of the following problem:

$$
\widetilde{G}\left(K_{t}, L_{t}, K_{t+1} ; \psi_{t}\right)=\max _{\nu_{t}} F\left(\nu_{t} K_{t}, L_{t}\right)-K_{t+1}+\left(1-\delta\left(\nu_{t}\right)\right) K_{t},
$$

with $\frac{\partial \delta\left(\nu_{t}\right)}{\partial \nu_{t}}>0$ and where $\nu$ is the rate of capacity utilization. The function $\widetilde{G}(\cdot)$ also allows to encompass models with "generalized intertemporal adjustment costs", where the accumulation equation is of the form:

$$
K_{t+1}=\left[I_{t}^{\rho}+\left((1-\delta) K_{t}\right)^{\rho}\right]^{\frac{1}{\rho}}, \quad \rho<1 .
$$

\footnotetext{
${ }^{3}$ In Beaudry and Portier [2004a] we illustrated a decreasing returns to scale environment where the temporary equilibrium had the property that $\frac{\partial C}{\partial I}=0$ and $\frac{\partial L}{\partial I}>0$, and hence does not satisfy the more stringent conditions for Expectation Driven Business Cycles we are examining here.

${ }^{4}$ One could think more generally of a set of the form $\widehat{G}\left(C_{t}, K_{t+1}, K_{t}, L_{t}\right) \leq 0$, where this set is convex, with $\widehat{G}_{1}, \widehat{G}_{2}>0, \widehat{G}_{3}, \widehat{G}_{4}<0$. But then one can always redefine a $\widetilde{G}$ as $\max C_{t}$ s.t $\widehat{G}\left(C_{t}, K_{t+1}, K_{t}, L_{t}\right) \leq 0$.
} 
In the cases where we use this more general structure, we can say that Expectation Driven Business Cycles can potential arise if the the surface defined by

$$
\begin{aligned}
U_{2}\left(C_{t}, 1-L_{t}\right) & =U_{1}\left(C_{t}, 1-L_{t}\right) \widetilde{G}_{L}\left(K_{t}, L_{t}, K_{t+1} ; \psi_{t}\right) \\
C_{t} & =\widetilde{G}\left(K_{t}, L_{t}, K_{t+1} ; \psi_{t}\right)
\end{aligned}
$$

has the property that $\frac{\partial C_{t}}{\partial K_{t+1}}>0$ and $\frac{\partial L_{t}}{\partial K_{t+1}}>0$.

\section{Can Expectation Driven Business Cycles arise in the Walrasian Equilibrium of One- or Two-Sector Macro Model?}

We first state a general necessary condition for the existence of Expectation Driven Business Cycles. Then, we prove two negative result: Expectation Driven Business Cycles cannot arise in one and two-sector standard models.

\subsection{A Necessary Condition for the Existence of Expectation Driven Business Cycles}

Let us first consider the case where current production possibilities can be represented by $C_{t}=$ $G\left(K_{t}, L_{t}, I_{t}\right)$ and where accumulation is $K_{t+1}=I+(1-\delta) K_{t}$.

Proposition 1 An economy can exhibit Expectation Driven Business Cycles only if $G_{L I}>0$.

Proof of proposition 1]: By fully differentiating (4) (with $d K=d \psi=0$ ), we obtain

$$
d L=\kappa_{1}\left(-\kappa_{2} d C+\kappa_{3} d I\right)
$$

with

$$
\left\{\begin{array}{l}
\kappa_{1}=-\left(G_{L} U_{C L}+U_{C} G_{L L}+U_{L L}\right)^{-1}>0, \\
\kappa_{2}=G_{L} U_{C C}+U_{L C}<0, \\
\kappa_{3}=U_{C} G_{L I} \lesseqgtr 0 .
\end{array}\right.
$$

Taking now the full differentiation of (5) and using (11), we get

$$
\frac{d C}{d I}=\frac{G_{I}+G_{L} \kappa_{1} \kappa_{3}}{1-G_{L} \kappa_{1} \kappa_{2}}
$$


If $G_{L I}<0$, then $\kappa_{3}<0$ and $\frac{d C}{d I}<0 . Q E D$

If we consider the more general case where production possibilities are represented by $C_{t}=$ $\widetilde{G}\left(K_{t}, L_{t}, K_{t+1}\right)$, the we have the following proposition.

Proposition 2 An economy can exhibit Expectation Driven Business Cycles only if $\widetilde{G}_{L_{t}, K_{t+1}}>0$.

Proof of PROPOSITION 2: The proof is a straightforward extension of the proof of Proposition 1. $Q E D$

\subsection{One-Sector Models}

Propositions 1 and 2 allow us to prove the three following corollaries.

Corrollary 1 Expectation Driven Business Cycles cannot arise in one-sector models, even with convex cost of adjusting capital.

Proof of Corollary 1 : In a one-sector model and in a one-sector model with convex adjustment costs, $G_{L I}=0$ and hence by Proposition 1 such economies cannot support Expectation Driven Business Cycles. QED

Corrollary 2 Expectation Driven Business Cycles cannot arise in one-sector models where variable capacity utilization generates production possibilities given by

$$
\max _{\nu} F\left(\nu_{t} K_{t}, L_{t}\right)-K_{t+1}+\left(1-\delta\left(\nu_{t}\right)\right) K_{t}, \quad \frac{\partial \delta}{\partial \nu}>0
$$

Proof of Corollary 2 : By the envelop theorem, $\widetilde{G}_{K_{t+1}}=-1$ and hence $\widetilde{G}_{K_{t+1}, L_{t}}=0$. Therefore by Proposition 2, such an economy cannot exhibit Expectation Driven Business Cycles. QED.

Corrollary 3 Expectation Driven Business Cycles cannot arise in one-sector models where capital accumulation is of the form

$$
K_{t+1}=\left[I_{t}^{\rho}+\left((1-\delta) K_{t}\right)^{\rho}\right]^{\frac{1}{\rho}}, \quad \rho<1 .
$$


Proof of COROllary $3:$ In this case the function is given by $\widetilde{G}=F\left(K_{t}, L_{t}\right)-\left[\left(K_{t+1}\right)^{\rho}+\right.$ $\left.\left((1-\delta) K_{t}\right)^{\rho}\right]^{\frac{1}{\rho}}$. Hence $\widetilde{G}_{K_{t+1}, L_{t}}=0$, and once again by Proposition 2 Expectation Driven Business Cycles cannot arise. $Q E D$

The above results indicate that Expectation Driven Business Cycles cannot arise in most onesector models used in the macro literature. 5 We now turn to examining whether Expectation Driven Business Cycles could arise in two-sector models. One reason why it may be interesting to look into two-sector models is that Propositions 1 and 2 cannot be used to rule out Expectation Driven Business Cycles, as the following example makes clear. This example also shows that the necessary condition on the function $G$ is not an exotic one.

Suppose the production function for consumption goods is $C=K^{1-\alpha}\left(L^{c}\right)^{\alpha}$, that it is $I=\left(L^{I}\right)^{\gamma}$ for investment goods, and that $L^{C}+L^{I}=L$. Then the $G(\cdot)$ for this economy is $G(K, L, I)=$ $K^{1-\alpha}\left(L-I^{\frac{1}{\gamma}}\right)^{\alpha}$, which has $G_{L I}>0$. Note that the condition $G_{L I}>0$ is only a necessary condition, and we prove in the next section that it is not always sufficient. Typically, our results for two-sectors models show that one cannot obtain Expectation Driven Business Cycles in this specific example.

\subsection{Two-Sector models}

The interest in examining two-sector models is that potentially they satisfy the necessary condition given in Proposition 1 .

Let us define a two-sector model as a model where the production function for consumption goods and the production function for investment goods are distinct, that is, where the aggregate production possibility is given by

$$
\begin{array}{r}
G\left(K_{t}, L_{t}, I_{t}\right)=\max _{K_{t}^{C}, K_{t}^{I}, L_{t}^{C}, L_{t}^{I}} F^{C}\left(K_{t}^{C}, L_{t}^{C}\right) \\
\text { s.t. }\left\{\begin{array}{l}
F^{I}\left(K_{t}^{I}, L_{t}^{I}\right) \geq I_{t} \\
K_{t}^{C}+K_{t}^{I} \leq K_{t} \\
L_{t}^{C}+L_{t}^{I} \leq L_{t}
\end{array}\right.
\end{array}
$$

\footnotetext{
${ }^{5}$ As explained above, we are restricting ourselves to models where the stock of capital of period $t$ is the only state variable. A natural question is how robust are our results to a model with time to build, which is an often used model in the literature. In Appendix B, we show that Expectation Driven Business Cycles cannot arise in a time to build model.
} 
where $F^{C}\left(K^{C}, L^{C}\right)$ and $F^{I}\left(K^{I}, L^{I}\right)$ are constant returns to scale and concave production functions. Proposition 3 Expectation Driven Business Cycles cannot arise in two-sector models

Proof of Proposition 3 : To prove this proposition, it is helpful to work with the dual form of the temporary equilibrium. Accordingly, let $\Omega^{C}\left(w_{t}, r_{t}\right)$ represent the unit cost function for the consumption good sector (where $r$ is the rental rate of capital and $w$ in the wage rate) and let $\Omega^{I}\left(w_{t}, r_{t}\right)$ represent the unit cost function for the investment good sector. A temporary equilibrium, with the consumption good being the numéraire and with $q$ being the price of investment, must then satisfy the following set of 5 conditions:

$$
\begin{aligned}
\Omega^{C}\left(w_{t}, r_{t}\right) & =1 \\
\Omega^{I}\left(w_{t}, r_{t}\right) & =q_{t} \\
\Omega_{1}^{C}\left(w_{t}, r_{t}\right) C_{t}+\Omega_{1}^{I}\left(w_{t}, r_{t}\right) I_{t} & =L_{t} \\
\Omega_{2}^{C}\left(w_{t}, r_{t}\right) C_{t}+\Omega_{2}^{I}\left(w_{t}, r_{t}\right) I_{t} & =K_{t} \\
U_{2}\left(C_{t}, 1-L_{t}\right) & =w_{t} U_{1}\left(C_{t}, 1-L_{t}\right)
\end{aligned}
$$

Note that as before, taking $K_{t}$ as given, this system implicitly defines a set of values for $C_{t}, I_{t}$ and $L_{t}$ (as well as values for $r_{t}, w_{t}$ and $q_{t}$ ). The claim is that with this set, an increase in $I_{t}$ is necessarily associated with a decrease in either $C_{t}$ or $L_{t}$ or both. Let us prove this be contradiction. If we assume that $C_{t}, I_{t}$ and $L_{t}$ increase, then equation (17) implies (by normality of leisure and consumption) that $w_{t}$ increases. Then if $w_{t}$ increases, equation (13) implies that $r_{t}$ decreases, but then it is impossible to satisfy equation (16) given that concavity of the production function and constant returns to scale imply that $\Omega_{2,2}^{C}<0, \Omega_{1,2}^{C}>0, \Omega_{2,2}^{I}<0$ and $\Omega_{1,2}^{I}>0$. ${ }^{6}$ QED

\section{Multi-sector models}

We now consider a general multi-sectorial structure, for which we prove that Expectation Driven Business Cycles can arise under some conditions on the technology. Next, these conditions are

\footnotetext{
${ }^{6}$ This proposition can be easily generalized to models with adjustment costs and variable rates of utilization.
} 
interpreted and an example is provided. Finally, we relate our result with the structure of the phase diagram of the model.

\subsection{Setup}

Let us consider the following multi-sector environment with $N>0$ intermediate sectors. The setup will slightly generalize standard multi-sector models by treating intermediate goods firms as multiproduct producers that sell potentially different inputs to the consumption or investment sector. The total output of consumption good $C_{t}$ is given by an aggregator function $C_{t}=J^{C}\left(X_{1}, \ldots, X_{N}\right)$ where $X_{i}$ denotes the quantity of an intermediate good produced by sector $i$ for the consumption good sector.

Similarly, the investment good is produced by an aggregate of intermediate inputs, that is, $I_{t}=J^{I}\left(Z_{1}, \ldots, Z_{N}\right)$ where $Z_{i}$ denotes the quantity intermediate inputs produced by sector $i$ for the investment good sector. $J^{C}$ and $J^{I}$ are increasing, concave, and symmetric functions of their argument (i.e. they are invariant under permutation of their argument) and that they are twice continuously differentiable and homogeneous of degree one.

Each intermediate good sector $i$ can produce $X$ and $Z$ according to

$$
H\left(X_{i}, Z_{i}\right)=F\left(K_{i}, L_{i}\right)
$$

where $F(\cdot)$ is a CRS and concave function, $H(\cdot)$ is a CRS convex function, and $K_{i}$ and $L_{i}$ represent the amount of labor and capital used in sector $i$.

In most multi-sector models used in macro, the function $H\left(X_{i}, Z_{i}\right)$ is simply the linear function $X_{i}+Z_{i}$. For this case, we have the following proposition.

Proposition 4 Expectation Driven Business Cycles cannot arise in a multi-sector setting if $H(\cdot)$ is linear.

Proof of Proposition 4: In this case because of symmetry, the model collapses to a twosector model and the proof of Proposition 3 applies. QED 
All the above results suggest that Expectation Driven Business Cycles can never arise. However, the following Proposition actually provides conditions under which Expectation Driven Business Cycles can arise.

Proposition 5 Expectation Driven Business Cycles can arise in a multi-sector setting if the following condition is satisfied.

$$
L \frac{F_{L L}}{F_{L}}-\left(L \frac{F_{L}}{F}\right)\left(X \frac{H_{X, Z}}{H_{Z}}\right)\left(\frac{H}{X H_{X}}\right)>L \frac{U_{L, L}}{U_{L}}-L \frac{U_{C, L}}{U_{L}}, \quad \text { when } \quad X=C \quad \text { and } \quad Z=I .
$$

ProOF OF PROPOSITION 3: In this case, because of symmetry, the temporary equilibrium can be reduced to the following two conditions:

$$
\left\{\begin{array}{l}
H\left(C_{t}, I_{t}\right)=F\left(K_{t}, L_{t}\right) \\
\frac{-U_{L}\left(C_{t}, 1-L_{t}\right)}{U_{C}\left({ }_{t} C, 1-L_{t}\right)}=\frac{F_{L}\left(K_{t}, L_{t}\right)}{H_{C}\left(C_{t}, I_{t}\right)}
\end{array}\right.
$$

Taking the total differential of this system to obtain $\frac{d C}{d I}$, and setting this greater than zero gives the above condition after manipulation. QED

Here we see that a necessary condition for Expectation Driven Business Cycles is that $H_{X, Z}$ be negative. One way to understand this necessary condition is in terms of decreasing returns. Given the fixed technology, if one increases investment $I$, one has to reduce consumption $C$ or leisure $1-L$. Given that we are assuming decreasing marginal rate of transformation between investment and leisure, it must be also be the case that we have a decreasing marginal rate of transformation between investment and consumption, otherwise all the adjustment will be done in terms of consumption.

More generally, the above condition is rather hard to interpret, especially the left side of the inequality. The right side of the inequality has an easy interpretation as the inverse of the intertemporal elasticity of labor supply (that is, the elasticity of the consumption constant labor supply). Hence a high labor supply elasticity makes this condition less stringent. In order to better understand the term of the right side, it is useful to expresses it terms of properties of an intermediate goods firm short run cost function. 


\subsection{Interpretation}

Let us define an intermediate goods firm short run cost function, $\Omega(X, Z, K, w)$, as follows:

$$
\left\{\begin{aligned}
\Omega(X, Z, K, w) & =\min _{L} w L \\
\text { s.t. } \quad H(X, Z) & =F(K, L)
\end{aligned}\right.
$$

Proposition 6 The intermediate firm's production function and its associated cost function satisfy the following relationship

$$
L \frac{F_{L L}}{F_{L}}-\left(L \frac{F_{L}}{F}\right)\left(X \frac{H_{X, Z}}{H_{Z}}\right)\left(\frac{H}{X H_{X}}\right)=\frac{\left(X \frac{\Omega_{X, Z}}{\Omega_{Z}}\right)}{\left(X \frac{\Omega_{X}}{\Omega}\right)}
$$

Proof of Proposition 6: Let us set up the Lagrangian associated with the cost minimization problem $(Q)$ as $w L+\lambda(H(X, Z)-F(K, L))$. Then by the envelop theorem, $\Omega_{X}=\lambda H_{X}(X, Z)$ and $\Omega_{X, Z}=\frac{\partial \lambda H_{X}(X, Z)}{\partial Z}$. By totally differentiating the first order conditions associated with the minimization problem to get $\frac{\partial \lambda H_{X}(X, Z)}{\partial Z}$, we can rearrange terms to get the above expression. $Q E D$

From the above two propositions, we can see that a necessary condition for the multi-sector economy to possibly exhibit Expectation Driven Business Cycles is that $\Omega_{X, Z}$ be negative, that is, that the marginal cost of producing $X$ decreases with the production of $Z$. The property that a cost function for a multi-product good firm has a negative cross derivative is generally referred to as a cost complementarity property. Let us emphasize that this cost complementarity condition does not violate convexity of the cost function as long as $\left(\Omega_{X, Z}\right)^{2}<\left(\Omega_{X, X}\right)\left(\Omega_{Z, Z}\right)$. With this result in mind, we have the following corollary on the possibility of Expectation Driven Business Cycles:

Corrollary 4 If $U(C, I-L)=\log C+\theta(1-L)$ (i.e., Hansen-Rogerson preferences), then a multi-sector economy can exhibit expectation driven fluctuations if the cost function of intermediate good firms exhibits cost complementarity (that is $\Omega_{X, Z}<0$. )

Proof of Corollary 4: This follows directly from Propositions 6 and 5 when noticing that right side of the condition in Proposition 5 is zero with these preferences. $Q E D$ 
In the more general case where preferences do not satisfy Hansen-Rogerson, then the condition is that the cost complementarity be sufficiently large relative to the slope of the consumption-constant labor supply curve.

\subsection{An Example}

An example of a cost function exhibiting cost complementarity is given by

$$
\Omega(X, Z, K, w)=w K^{-\frac{1-\alpha}{\alpha}}\left(\left[X^{\sigma}+Z^{\sigma}\right]^{\frac{1}{\alpha \sigma}}\right), \quad 0<\alpha<1, \sigma>\frac{1}{\alpha}
$$

The associated production function is

$$
\left[X^{\sigma}+Z^{\sigma}\right]^{\frac{1}{\sigma}}=K^{1-\alpha} L^{\alpha}
$$

An interpretation of such a production function is the existence of multi-sectorial investment adjustment costs, and this structure has been used in the literature by Sims [1989], Vallés [1997] ), Huffman and Wynne [1999] and Kim [2003]. [7]

If one assumes that preferences are Hansen-Rogerson preferences $(U(C, I-L)=\log C+\theta(1-L))$, then, using Corrolary 4 it is straightforward to prove that economy exhibits Expectation Driven Business Cycles if $\sigma \geq \frac{1}{\alpha}$.

This result can be extended to the presence of variable capacity utilization. In such a case, the amount of curvature in the $H(\cdot)$ function needed to support Expectation Driven Business Cycles can be arbitrarily small (or one can assume an arbitrarily small multi-sectorial adjustment costs). To see this, assume the production function is

$$
\left[X_{t}^{\sigma}+Z_{t}^{\sigma}\right]^{\frac{1}{\sigma}}=\left(\nu_{t} K_{t}\right)^{1-\alpha} L_{t}^{\alpha}
$$

and the accumulation equation is

$$
K_{t+1}=I_{t}+\left(1-\delta_{0}-\frac{\nu_{t}^{1+\gamma}}{1+\gamma}\right) K_{t}, \quad \gamma \geq 0
$$

\footnotetext{
${ }^{7}$ It should be noted that such a aggregate production function is also found in Benhabib and Farmer [1996], but as the outcome of an equilibrium with sector-specific externalities.
} 
then the condition for Expectation Driven Business Cycles is $\frac{\sigma(1+\gamma)-1}{\gamma}>\frac{1}{\alpha}$. As $\gamma$ approaches zero (high elasticity of capacity utilization), $\sigma$ can approach 1.

\subsection{A General Necessary and Sufficient Condition}

We have now identified an environment which has the potential of supporting Expectation Driven Business Cycles, and we think that it is one which is easy to understand. However, this does not mean it is the only structure that can support Expectational Driven Fluctuations, and the following proposition states the necessary and sufficient condition for existence in the general case. Such a condition does not receive easy further interpretations than the one we gave before.

Proposition 7 When technology is given by $C_{t}=G\left(K_{t}, L_{t}, I_{t} ; \psi_{t}\right)$, the economy exhibits Expectation Driven Business Cycles if and only if

$$
G_{L I}>\frac{G_{I}\left(G_{L} U_{C L}+U_{C} G_{L L}+U_{L L}\right)}{G_{L} U_{C}}
$$

Proof of Proposition 7: The proof follows directly from the algebra of the proof of Proposition 1. QED

\subsection{A Graphical Illustration of the temporary equilibrium constraints}

Here, we present a graphical illustration of the temporary equilibrium conditions in four different models. The diagrammatical representation will be given in the space of consumption and labor, taking investment as an exogenous shifter. The four models we consider are: the standard one sector Walrasian model, a model with increasing returns to scale, a model with sticky prices and a Walrasian model with a technology which satisfies Proposition 7.

One-Sector Model : In a standard one-sector model, the temporary equilibrium is the triplet $\left(C_{t}, L_{t}, I_{t}\right)$ that satisfies the following Good Market equilibrium condition $(G M)$ and labor market equilibrium equilibrium condition $(L M)$ :

$$
C_{t}+I_{t}=F\left(K_{t}, L_{t}\right)
$$




$$
U_{C}\left(C_{t}, 1-L_{t}\right) F_{L}\left(K_{t}, L_{t}\right)=-U_{L}
$$

For a given level of investment $I_{t}$ (that depends on expectations), those two locus can be represented on a $(C, L)$ plane. Full differentiation of $(G M)$ gives

$$
d C_{t}+d I_{t}=F_{L} d L_{t}
$$

The $(G M)$ curve is upward sloping, and shifts to the north-west when $I$ increases.

Full differentiation of $(L M)$ gives

$$
\left(U_{C} F_{L L}+U_{L C} F_{L}+U_{L L}\right) d L_{t}+\left(U_{C C} F_{L}+U_{L C}\right) d C_{t}=0
$$

Given quasi-concavity of $U$ and $F$, the $L M$ curve slopes down, and is not affected by a change in investment $I$. Those two curves are depicted on Figure 3. It is easy to see from this Figure that Expectation Driven Business Cycles cannot occur. An increase in investment $d I>0$ moves the economy from temporary equilibrium $E$ to temporary equilibrium $E^{\prime}$. As $L M$ is downward sloping, employment increases but consumptions decreases from $E$ to $E^{\prime}$

A Model with Increasing Returns : Here we consider a simple analytic version of Benhabib and Farmer [1994]. Although the result can be obtained without specifying analytical forms, we assume quasi-linear preferences

$$
U\left(C_{t}, 1-L_{t}\right)=\log \left(C_{t}\right)+B\left(1-L_{t}\right)
$$

and a production function with constant private returns to scale and constant social returns to scale:

$$
Y_{i, t}=K_{i, t}^{\alpha} L_{i, t}^{1-\alpha}\left(K_{t}^{\alpha^{\prime}} L_{t}^{\beta}\right)
$$

where $L_{t}$ and $K_{t}$ stand for aggregate levels and $K_{i, t}, L_{i, t}$ for individual ones. There is a continuum of measure 1 of competitive firms, that take aggregate levels as given. We consider symmetrical equilibrium allocations. The temporary equilibrium of this economy can be shown to be the triplet 
$\left(C_{t}, L_{t}, I_{t}\right)$ that satisfies a $(G M)$ and a $(L M)$ equation, that can be written after some algebraic manipulations

$$
\begin{gathered}
d C_{t}+d I_{t}=(1-\alpha+\beta) \frac{Y_{t}}{L_{t}} d L_{t} \\
d C_{t}=(\beta-\alpha) \frac{C_{t}}{L_{t}} d L_{t}
\end{gathered}
$$

As in the standard model, the GM curve slopes up, and shift to the North-West with $I$. Similarly, the $L M$ curve position is independent of $I$. If the externality on the labor input $\beta$ is mild (less than $\alpha$ ), the $L M$ curve slopes down, and there cannot be Expectation Driven Business Cycles. If the externality is large enough $(\beta>\alpha)$, then $L M$ slopes upwards. It is easy to check that in that case

$$
\frac{\text { slope of }(G M)}{\text { slope of }(L M)}=\frac{\beta-\alpha}{1+\beta-\alpha} \times \frac{C_{t}}{Y_{t}}<1
$$

so that $(L M)$ is steeper that $(G M) 8^{8}$ Those two curves are depicted on Figure 4 in the case $\beta>\alpha$. In such a model, Expectation Driven Business Cycles can occur as seen in the figure. In particular, an increase in investment corresponds to a shift along the upward sloping $(G M)$ condition and therefore is associated with a rise in both consumption and employment.

A Sticky-Price Model: Let us consider here a very simplified model with money. We assume standard preferences and technology. Money cannot be carried over from one period to another, is distributed in every period to household in a lump-sum way, and has a positive price because it is needed to buy consumption. In such a case, the household problem is given by

$$
\begin{array}{ll}
\max _{C, L, M^{d}} E_{0} \sum_{t} \beta^{t} U\left(C_{t}, L_{t}\right) & \\
\text { s.t. } & P_{t} C_{t}+P_{t} I_{t}+M_{t}^{d} \leq P_{t} w_{t} L_{t}+P_{t} z_{t} K_{t}+M_{t} \\
& K_{t+1} \leq(1-\delta) K_{t}+I_{t} \\
& P_{t} C_{t} \leq M_{t}^{d}
\end{array}
$$

where $P$ is the nominal price level, $w$ and $z$ are the real rental prices of labor and capital, $M^{d}$ nominal balances demand and $M$ the monetary lump-sum injection. On the firm side, we assume competitive behavior, so that the representative firm equalizes marginal productivity of factors with

\footnotetext{
${ }^{8}$ The condition $\beta>\alpha$ corresponds to the upward sloping labor demand condition of Benhabib and Farmer [1994].
} 
their rental price. In this economy, the flex-price temporary equilibrium allocations can be described by the following three equations, where $(M M)$ is the money market equilibrium condition:

$$
\begin{gathered}
C_{t}+I_{t}=F(K, L) \\
U_{C}(C, 1-L) F_{L}(K, L)=-U_{L} \\
C_{t}=\frac{M}{P_{t}}
\end{gathered}
$$

Not surprisingly, money in neutral in a temporary equilibrium: for a given level of investment $I_{t}$, $(G M)$ and $(L M)$ determine consumption and worked hours, while $(M M)$ sets the price level. We now assume that prices are preset, so that they are fixed in a temporary equilibrium. We also assume that when prices are not at their Walrasian levels, labor market allocations are always determined by labor demand. Under those conditions, a fix-price equilibrium is a $\left(C_{t}, L_{t}, I_{t}\right)$ that satisfies equations $(G M)$ and $(M M)$, the labor market being generically not in equilibrium.

Equations $(G M)$ and $(M M)$ are drawn on Figure 5. A shock on expectations that increases investment moves the economy from $E$ to $E^{\prime}$. As prices are fixed, consumption does not move. In a weak sense $(d I>0, d L>0$ and $d C \geq 0)$, one gets Expectation Driven Business Cycles. This fix-price temporary equilibrium allocation corresponds to the $I S-L M$ model in the specific case where money demand depends positively of consumption (and not total income), and is inelastic to the nominal interest rate. One could easily obtain a positively (but not infinitely) sloped $(M M)$ curve, and therefore the existence of Expectation Driven Business Cycles in a strong sense $((d I>0$, $d L>0$ and $d C>0)$ ) by allowing for a more richer modelling of money demand. 9 We think that this simple example is enough for the point we want to make.

Walrasian model with economies of scope: Here we make the use of our $G$ function terminology. The temporary equilibrium of this economy can be shown to be the triplet $\left(C_{t}, L_{t}, I_{t}\right)$ that satisfies a $(G M)$ and a $(L M)$ equation, that are given by

$$
C_{t}=G\left(K_{t}, L_{t}, I_{t}\right)
$$

\footnotetext{
${ }^{9}$ In the setting we have proposed here, including nominal labor income in the cash constraint would give rise to Expectation Driven Business Cycles in a strong sense.
} 


$$
U_{C}\left(C_{t}, 1-L_{t}\right) G_{L}\left(K_{t}, L_{t}, I_{t}\right)=-U_{L}\left(C_{t}, 1-L_{t}\right)
$$

As already noted, the simple one-sector model corresponds to the case $G_{I}=-1$. By full differentiation of $(G M)$, we obtain

$$
d C_{t}=G_{L} d L_{t}+G_{I} d I_{t}
$$

The $(G M)$ curve is again upward sloping, and shifts to the north-west when $I$ increases because $G_{I}<0$. Full differentiation of $(L M)$ gives

$$
\left(U_{C} G_{L L}+U_{L C} G_{L}+U_{L L}\right) d L+\left(U_{C C} G_{L}+U_{L C}\right) d C_{t}+U_{C} G_{L I} d I_{t}=0
$$

Given quasi-concavity of $U$ and $F$, the $L M$ curve slopes down again. What is different is that it is affected by a change in investment $I$ : an increase in investment shift the curve to the North-East if $G_{L I}$ is positive. In the standard one sector model this was not the case as $G_{L I}=0$. Those two curves are depicted on Figure 6. A necessary condition for the occurrence of Expectation Driven Business Cycles is that the $L M$ curve shifts to the North-East for $d I>0$. A sufficient condition is that it shifts enough, to guarantee that $E^{\prime}$ is in the positive orthant with origin $E$. This sufficient conditions involves $G_{L I}$ and the slope of $(G M)$. In words, $G_{L I}$ should be large enough.

\subsection{Expectation Driven Fluctuation and the Structure of Phase Diagrams}

Phase diagrams are often used in economics as a tool for understanding how dynamic systems, with forward looking components, react to announcements of a future changes in fundamentals. In particular, in the case of a saddle path stable equilibrium, the properties of the system's dynamics between the time of an announcement and the implementation of the announced change are governed entirely by the properties of the system's unstable paths. In effect, following an announcement, the perfect foresight path in a stable equilibrium involves a jump to an unstable path and an evolution along that path until the announced change takes effect; hence these dynamics can be captured in a phase diagram. As is well known, the dynamics induced by announcements mimic closely the dynamics induced by an expected change in fundamentals in a stochastic version 
of the same system. For this reason, it is of interest to examine the link between the conditions derived in section 4 and the nature of the phase diagram of the continuous time market economy which satisfies these conditions. For example, by examining the properties of the associated system's phase diagram we will be able to show that our conditions for the possibility of Expectation Driven Business Cycles translate in to a particular structure for the unstable paths. In effect, our condition for the possibility of Expectation Driven Business Cycles produces unstable paths that necessarily involve positive co-movement between consumption and capital (as well as investment and employment) when starting from the steady state.

Let us begin by reviewing the nature of the phase diagram of a one-sector model with the preferences of the representative household given by

$$
\int_{0}^{\infty} U\left(C_{t}, 1-L_{t}\right) \exp ^{\rho t} d t
$$

with $U\left(C_{t}, 1-L_{t}\right)$ satisfying the conditions outlined in section 2 (i.e., quasi concavity and normality of goods). Technology is given by a constant returns to scale and concave producing function $F\left(K_{t}, L_{t}\right)$ and capital accumulated according to

$$
\dot{K}=I-\delta K
$$

Under these conditions, it is easy to verify that the phase diagram associated with the Walrasian equilibrium of such an economy will take the form depicted in Figure 1 in the proximity of the steady state. As can be seen in this Figure, the stable arm of the system is positively sloped and the unstable arm is negatively sloped. Therefore, in such a system, if there is an announcement when the system is initially in its steady state, it will necessarily induce negative co-movements between consumption and capital accumulation. For example, without needing to specify the source of the announcement, we know that if the announcement leads to a jump up in consumption, it places the system on a path with increasing consumption but falling capital, that is a path with negative co-movement between consumption and capital. If the announcement leads to a negative jump in consumption, it places the system on a path of falling consumption and increasing capital. Hence, regardless of the source of the announcement, in creates negative co-movement. 
Let us now contrast the properties of the phase diagram in Figure 1 with that of a economy with the same preferences and accumulation structure, but where the technological opportunities are instead described by the set $C_{t} \leq G\left(K_{t}, L_{t}, I_{t}\right)$ where $G(\cdot)$ satisfies the condition $G_{L I}>\frac{G_{I}\left(G_{L} U_{C L}+U_{C} G_{L L}+U_{L L}\right)}{G_{L} U_{C}}$, which has be proven to be the necessary and sufficient condition for the existence of Expectation Driven Business Cycles in Proposition 7, In this case, the $\dot{K}=0$ is implicitly defined by the system of three equations, $I-\delta K=0, \quad C=G(K, L, I), \quad-U_{L}(C, 1-L)=$ $G_{L}(K, L, I) U_{C}(C, L)$. Those equations imply that $\frac{\partial C}{\partial K}>0$. Therefore, the slope of this locus remains positive, but the space above it is now associated with decreases in $K$. Hence, the stable arm maintains a positive slope, but with a slope which is smaller that that of the $\dot{K}=0$ locus. Given that the system is saddle path stable, in this case the unstable arm must have a positive slope that is greater the slope of the $\dot{K}=0$ locus. Consequently, the configuration of the phase diagram is as depicted in Figure 2 .

There are two main aspects to note when comparing Figures 1 and 2 . First, both have positively sloped stable arms and hence their transitional dynamics have similar quantitative properties 10 Second, and most important, the slopes of the unstable paths above and below the system's steady state are reversed. In Figure 2, when starting at the steady state, any announcement will induce a positive co-movement between consumption and capital. In effect, if the announcement leads to a jump up in consumption, it will be followed by further increases in consumption and capital. Similarly, if the announcement leads to a decrease in consumption, it will again lead to a positive co-movement between consumption and capital. Hence, in this case, we can unambiguously say that announced changes in fundamentals creates positive co-movement between consumption and capital and therefore announced changes (or expected changes) in fundamentals in this setting are potential sources of business cycle type fluctuations. Note that such positive co-movement between $\mathrm{C}$ and $\mathrm{K}$ induced by announcements in Figure 2 should not be surprising given that the

\footnotetext{
${ }^{10}$ Even though the transitional dynamics of both systems is governed by a positively slope stable arm, their transitional dynamics are not identical. In the transitional dynamics underlying Figure 1, there is a negative comovement between the growth rate of consumption and the growth rate of investment, while it is positive in Figure 2 .
} 
condition $G_{L I}>\frac{G_{I}\left(G_{L} U_{C L}+U_{C} G_{L L}+U_{L L}\right)}{G_{L} U_{C}}$ guarantees a positive co-movement between the growth of consumption and the growth of investment on all the trajectories (stable and unstable) in Figure 2, since all these trajectories must belong to the same temporary equilibrium surface.

As a last note on the phase diagram, it is of interest to note how the system depicted in Figure 2 would evolve following an announced change that is eventually not realized. 11 In this case, the economy would appear to go through a cycle, either starting by a boom followed by a bust, or starting by a bust and then a boom.

\section{A Complete Example of Expectation Driven Business Cycles under Rational Expectations}

Up to now, we have identified a set of properties that a model must satisfy if changes in expectations are to cause positive co-movement between consumption, investment and employment. In this section we present a fully developed example whereby Expectation Driven Business Cycles arise under rational expectations. For this to be possible, two conditions must be met. One the one hand, there must be a driving force which is at least partially predictable in order to have an independent role for expectations. Second, the environment must satisfy the conditions outlined in section 4, which implies the presence of more than one sector. One possibility would be to consider the effect of expected changes in technology. However, given we are in a multi-sector environment, modelling an expected technological change is complicated by the fact that we must specify which sector is affected and that the results are sensitive to such specification 12 We choose to focus on tax changes in order to bypass this difficulty and to allow a better understanding of the mechanisms. We will assume that agents receive information about a tax change before it is actually implemented. Hence, agents will react to this information, which will be the underlying fundamental driving force behind

\footnotetext{
${ }^{11}$ Our interest in this case is that such a sequence of events corresponds rather closely to what would happen in this system if agents make an expectation error, that is, if agents expect a change in fundamentals and such a change does not materialize.

12 For example, expected technological change in the capital goods producing sector generally causes a recession, while expected technological change in the consumption good sector can generate a boom.
} 
expectations. On the production side, we will adopt the multi-sector (or intratemporal adjustment cost) framework presented in the example in section 4. We will compare the behavior of the model under the assumption that $\sigma=1$ (one-sector or no intratemporal adjustment cost) and the case where $\sigma>1$, for both the cases when the tax change in anticipated and when it is not. As we will see, the models' implications are almost identical when the tax change is an entirely unanticipated shock, but that the two models (i.e., models having different $\sigma$ ) differ dramatically in their responses to news about future tax changes.

The non-stochastic aspects of the model are standard in that we assume that instantaneous utility is given by $\log C_{t}+\eta\left(1-L_{t}\right)$. The only non-standard feature of the model is the specification of the aggregate production function, which is given by $\left(a C_{t}^{\sigma}+b I_{t}^{\sigma}\right)^{\frac{1}{\sigma}}=A\left(K_{t} \mu_{t}\right)^{1-\alpha}\left(X_{t} L_{t}\right)^{\alpha}$. Note that $\sigma=1$ corresponds to the standard one-sector model. As explained in section $4, \sigma>1$ can be interpreted as reflecting the presence of firms with economies of scope.

We introduce into this economy a capital income tax $\tau_{k t}$ and a labor income tax $\tau_{\ell t}$, and we assume that the proceeds of those taxes are redistributed to households in a lump sum way. Hence, these taxes simply create distortions in the economy and have no other role. In such a case, it is straightforward to verify that the walrasian equilibrium allocations are the solution to the following set of equations:

$$
\begin{aligned}
U_{1}\left(C_{t}, 1-L_{t}\right) G_{L}\left(K_{t}, L_{t}, I_{t}\right)\left(1-\tau_{\ell t}\right)= & U_{2}\left(C_{t}, 1-L_{t}\right) \\
C_{t}= & G\left(K_{t}, L_{t}, I_{t}\right) \\
U_{1}\left(C_{t}, 1-L_{t}\right)= & \beta E_{t}\left[U _ { 1 } ( C _ { t _ { 1 } } , 1 - L _ { t + 1 } ) \left(\frac{G_{K}\left(K_{t+1}, L_{t+1}, I_{t+1}\right)\left(1-\tau_{k t+1}\right)}{-G_{I}\left(K_{t}, L_{t}, I_{t}\right)}\right.\right. \\
& \left.\left.+(1-\delta) \frac{G_{I}\left(K_{t+1}, L_{t+1}, I_{t+1}\right)}{G_{I}\left(K_{t}, L_{t}, I_{t}\right)}\right)\right] \\
K_{t+1}= & I_{t}+(1-\delta) K_{t} .
\end{aligned}
$$

The parameters values we use are presented in table 1 1 . The length of a period is set at a quarter. The parameters $(\alpha, \delta, \eta, \beta, \gamma)$ are set to values commonly accepted in the literature. The parameters $a$ and $b$ of the aggregate production function are set to one, so that we have 
the standard one-sector model when $\sigma=1$. In the case with productive complementarity, we assume that $\sigma=1.65$, which is slightly above the limit value $1 / \alpha(=1.5)$ that we have computed in the previous section. Using the same functional form of intratemporal adjustment costs, Vallés [1997] calibrates $\sigma$ to match the estimated responses of investment to three shocks: a preference shock, a technological shock and a shock to intratemporal adjustment costs. He obtains a value $\sigma=1.8$. A specification similar to our is also used in Sims [1989], where it is assumed there, without justification, that $\sigma=3$.

We assume an initial $20 \%$ uniform income taxation, so that $\tau_{\ell}=\tau_{k}=20 \%$. The shock is a permanent four hundred basis points cut in both tax rate (from $20 \%$ to 16\%). This shock is either a surprise in period one; or is announced in period one and implemented five periods ahead. Of course, a more complex shock structure would be needed to reproduce fluctuations, allowing also for technology shocks, noisy signals and gradual resolution of uncertainty (see Beaudry and Portier [2004a] for a richer modeling of the informational structure in a setup with news about future productivity growth). Here, we are only interested in conditional responses to news, we think it is more illustrative to keep a simple shock structure.

We check that with those parameters, consumption represents $75 \%$ of output, capital is 9.18 times quarterly output, the labor share is two-thirds and the steady state level of worked hours is $18 \%$ of the period time endowment.

Table 1: Parameters Values

\begin{tabular}{clc}
\hline \hline$\sigma$ & degree of productive complementarity & 1 or 1.65 \\
$\alpha$ & share of labor icome & $2 / 3$ \\
$n$ & \# of periods in advance the news occurs & 5 \\
$\delta$ & depreciation rate & .125 \\
$\eta$ & disutility of leisure parameter & 5 \\
$\beta$ & psychological discount factor & .9899 \\
$a$ & production function parameter & 1 \\
$b$ & production function parameter & 1 \\
\hline \hline
\end{tabular}


Given those parameters values, we solve for the Walrasian equilibrium by log-linearizing equations (18) - (21) to obtain an approximate solution to the model. We then compute impulse response functions for the model with and without economies of scope.

\subsection{Responses To a Tax Cut Surprise and to a Tax Cut News}

Let us first consider responses to a tax surprise in the two cases $\sigma=1$ (standard one-sector model) and $\sigma=1.65$ (multi-sector model with economies of scope). Four variables are plotted in figure 7) the income tax rate, worked, hours, consumption and investment. Each variable is expressed in percentage deviation from the initial steady-state. In both versions of the model, an unanticipated permanent decrease in the income tax rate permanently increases consumption, investment and hours. The qualitative response of all variables is similar in both versions of the model, as the tax cut surprise creates an aggregate boom. In the case with $\sigma=1$, investment and hours overshoot in order to smooth consumption. Notice that in the multi-sector case, the productive complementarity dampens investment response and pushes up the response of consumption. This comes from the fact that there is less of a tradeoff here between investment and consumption.

We now turn to a tax cut announcement in period 1, that is implemented in period 6 . Figure 8 presents the responses of the four variables under consideration during the interim periods (the first five periods), i.e. between the announcement date and the implementation of the tax cut. The two models are now qualitatively very different. In the case of $\sigma=1$, consumption increases on impact because of a wealth effect, stays above its initial steady state level but decreases after period 1 until the tax cut is effectively implemented. Simultaneously, investment and hours decrease on impact and during interim periods. Therefore, the announced reduction in distortionary taxes creates a recession in output, investment and hours. In contrast, the figure shows that in the multi-sector model all variables increase on impact and during the interim periods: hence the tax cut announcement creates an expectation driven aggregate expansion. 


\section{Conclusion}

In this paper, we have shown that: (1) Expectation Driven Business Cycles are possible in simple neo-classical settings, meaning that strictly positive co-movement between consumption, investment and employment can arise in simple perfect market settings as the result of changes in expectation; and (2) most commonly used macro models restrict the production possibility set in a manner that precisely rules out the possibility of Expectation Driven Business Cycles in the presence of market clearing. The main technological features we identified as being necessary for Expectation Driven Business Cycles is that of a multi-sector setting where where firms experience economies of scope.

In closing, let us emphasize that a model which allows for Expectation Driven Business fluctuations is a close cousin to a simple Keynesien cross model since in both cases an autonomous increase in investment leads to a more than one-for-one increase in output. Our results therefore can be thought as linking the possibility of Keynesian Cross type phenomena with a technological feature that is close in spirit to those emphasized in the Complementarity and Coordination literature 13. In particular, our results identify technological conditions under which business cycles may arise as a purely demand driven phenomena, as in traditional Keynesian models, even in the absence of sticky prices, imperfect competition, increasing returns to scale or externatilities. In this sense, our analysis highlights a new mechanism which may help explain why market economies may exhibit business cycle fluctuations driven by changes in expectations.

\section{References}

BAsu, S. (1996): "Procyclical Productivity: Increasing Returns or Cyclical Utilization?," The Quarterly Journal of Economics, 111(3), 719-751.

Basu, S., and J. Fernald (1997): "Returns to Scale in U.S. Production: Estimates and Implications," Journal of Political Economy, 105(2), 249-283.

\footnotetext{
${ }^{13}$ See Cooper [1999] for an exposition of that literature.
} 
Beaudry, P., and F. Portier (2004a): “An Exploration into Pigou's Theory of Cycles," Journal of Monetary Economics, 51(6), 1183-1216.

(2004b): "News, Stock Prices and Economic Fluctuations," Working Paper 10548, National Bureau of Economic Research.

Benhabib, J., And R. FARmer (1994): "Indeterminacy and increasing returns," Journal of Economic Theory, 63(1), 19-41.

- (1996): "Indeterminacy and sector-specific externalities," Journal of Monetary Economics, $37(3), 421-443$.

Burnside, C., M. Eichenbaum, and S. Rebelo (1995): "Capital Utilization and Returns to Scale," NBER Macroeconomics Annual 1995, pp. 67-109.

Christiano, L., And R. Todd (19976): "Time to Plan and Aggregate Fluctuations," Quarterly Review of the Federal Reserve Bank of Minneapolis, 20(1), 14-27.

Cooper, R. (1999): Coordination Games : Complementarities and Macroeconomics. Cambridge University Press, Cambridge, Mass.

Huffman, G., And M. Wynne (1999): "The role of intratemporal adjustment costs in a multisector economy," Journal of Monetary Economics, 43, 317-350.

KIM, J. (2003): "Functional equivalence between intertemporal and multisectoral investment adjustment costs," Journal of Economic Dynamics and Control, 27, 533-549.

Kydland, F., and E. Prescott (1982): "Time to Build and Aggregate Fluctuations," Econometrica, 50(6), 1345-1370.

Sims, C. (1989): "Models and their Uses," American Journal of Agricultural Economics, pp. 489494. 
VALLÉS, J. (1997): "Aggregate investment in a business cycle model with adjustment costs," Journal of Economic Dynamics and Control, 21, 1181-1198. 


\section{Appendix}

\section{A Another Formulation of the Expectation Driven Business Cy- cles}

In this appendix, we explicitly consider the fact that agents at time $t$ have a (possibly subjective) distribution for $\psi_{t+1}$ and $I_{t+1}$, that is, they are endowed with a joint probability density function for these two variables, which we denote by $\Phi\left(\psi_{t+1}, I_{t+1}\right)$. In this case, the conditions

$$
\begin{aligned}
U_{2}\left(C_{t}, 1-L_{t}\right) & =U_{1}\left(C_{t}, 1-L_{t}\right) G_{L}\left(K_{t}, L_{t}, I_{t} ; \psi_{t}\right) \\
C_{t} & =G\left(K_{t}, L_{t}, I_{t} ; \psi_{t}\right) \\
U_{1}\left(C_{t}, 1-L_{t}\right) & =\beta E_{t}\left[u_{1}\left(C_{t_{1}}, 1-L_{t+1}\right)\left(\frac{G_{K}(t+1)}{-G_{I}(t)}+(1-\delta) \frac{G_{I}(t+1)}{G_{I}(t)}\right)\right] \\
K_{t+1} & =I_{t}+(1-\delta) K_{t} .
\end{aligned}
$$

plus the two conditions

$$
\begin{aligned}
U_{2}\left(C_{t+1}, 1-L_{t+1}\right) & =U_{1}\left(C_{t+1}, 1-L_{t+1}\right) G_{L}\left(K_{t+1}, L_{t+1}, I_{t+1} ; \psi_{t+1}\right) \\
C_{t+1} & =G\left(K_{t+1}, L_{t+1}, I_{t+1} ; \psi_{t+1}\right)
\end{aligned}
$$

simultaneously define a distribution for $C_{t+1}$ and $L_{t+1}$, as well as values for $L_{t}, I_{t}, K_{t+1}, C_{t}$ as a function of $\Phi(\cdot)$. Then, in this framework, we can ask when can a change in $\Phi(\cdot, \cdot)$ leads to a positive co-movement between $L_{t}, I_{t}, K_{t+1}, C_{t}$. The answer is precisely when the surface defined by the two equations $(4)$ and $(5)$ of the main text has the property that $\frac{\partial C}{\partial I}>0$ and $\frac{\partial L}{\partial I}>0$.

\section{B A Model with Time to Build}

Here we examine a time to build model that possesses more than one state variable. The model can be described as follows. Preferences have the standard form.

$$
E_{0} \sum_{t=0}^{\infty} \beta^{t} U\left(C_{t}, 1-L t\right) .
$$


Output is produced according to

$$
Y_{t}=F\left(K_{t}, L_{t}\right)
$$

To model time to build, we use the formulation of Kydland and Prescott [1982] and Christiano and Todd [19976]. Investment in period $t$ is given by

$$
I_{t}=\sum_{j=1}^{n} \omega_{j} S_{j, t}
$$

where $S_{j t}$ is the volume of projects $j$-periods away from completion at the beginning of period t and $\omega_{j}$ is the resource cost associated with work on a project $j$ periods away from completion, for $j=1, \ldots, n$. Investment projects progress according to

$$
S_{j, t+1}=S_{j+1, t} \text { for } 1<j \leq n
$$

and starts during period $t$ are represented by $S_{n, t}$. Thus the capital stock evolves according to

$$
K_{t+1}=(1-\delta) K_{t}+S_{1, t}
$$

In the following, we restrict ourselves to $n=2$ without loss of generality for the result. The optimal allocation program can be reduced to $\max _{S_{2, t}, L_{t}} E_{0} \sum_{t=0}^{\infty} \beta^{t} U\left[F\left[(1-\delta) K_{t-1}+S_{2, t-2}, L_{t}\right]+(1-\delta)\left((1-\delta) K_{t-1}+S_{2, t-2}\right)-\omega_{1} S_{2, t-1}-\omega_{2} S_{2, t}, 1-L_{t}\right]$ with $K_{0}$ and $S_{1,0}$ given. The first-order conditions associated with this program are

$$
\begin{gathered}
C_{t}+\omega_{1} S_{1, t}+\omega_{2} S_{2, t}=F\left(K_{t}, L_{t}\right) \\
U_{1}\left(C_{t}, 1-L_{t}\right) F_{2}\left(K_{t}, L_{t}\right)=U_{2}\left(C_{t}, 1-L_{t}\right) \\
U_{1}\left(C_{t}, 1-L_{t}\right) \omega_{2}+\beta E_{t}\left[U_{1}\left(C_{t+1}, 1-L_{t+1}\right) \omega_{1}\right]=\beta^{2} E_{t}\left[U_{1}\left(C_{t+2}, 1-L_{t+2}\right)\left(F_{1}\left(K_{t+2}, L_{t+2}\right)+1-\delta\right)\right]
\end{gathered}
$$

and a transversality condition. 
In a given period $t, K_{t}$ and $S_{1, t}$ are given. A temporary equilibrium of this economy is a triplet $\left(C_{t}, L_{t}, S_{2, t}\right)$ that satisfies equations (33) and (34). Here, $S_{2, t}$ stands for new investment. Let us define the $G$ function as

$$
C_{t}=G\left(K_{t}, L_{t}, S_{1, t}, S_{2, t}\right)=F\left(K_{t}, L_{t}\right)-\omega_{1} S_{1, t}-\omega_{2} S_{2, t}
$$

As previously shown, a necessary condition for Expectation Driven Business Cycles is $G_{L S_{2}}>0$. In the time to build model $G_{L S_{2}}=-\omega_{2}<0$, so that one cannot generate Expectation Driven Business Cycles.

\section{Figures}

Figure 1: Phase Diagram in a One-Sector Model

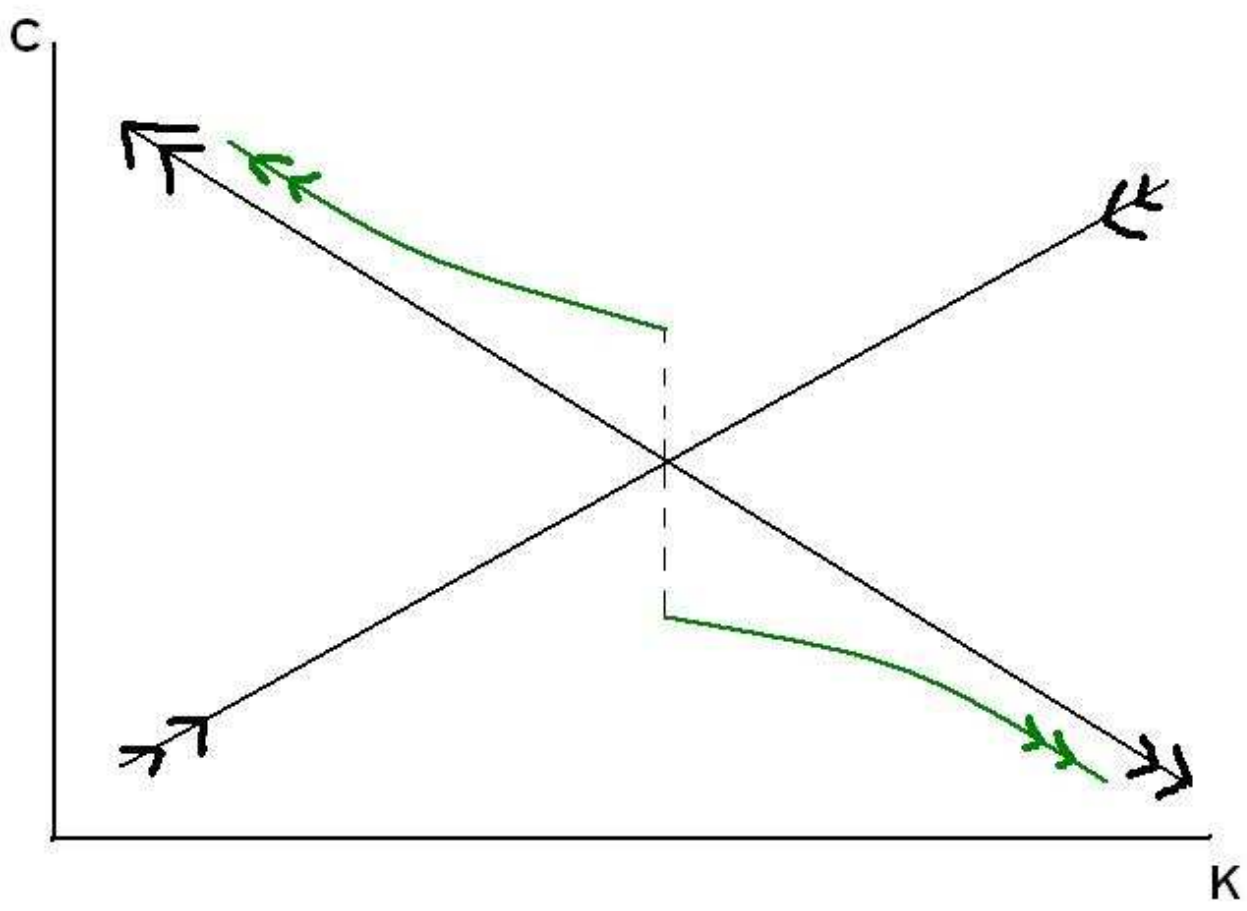


Figure 2: Phase Diagram in a $G$ Model Economy

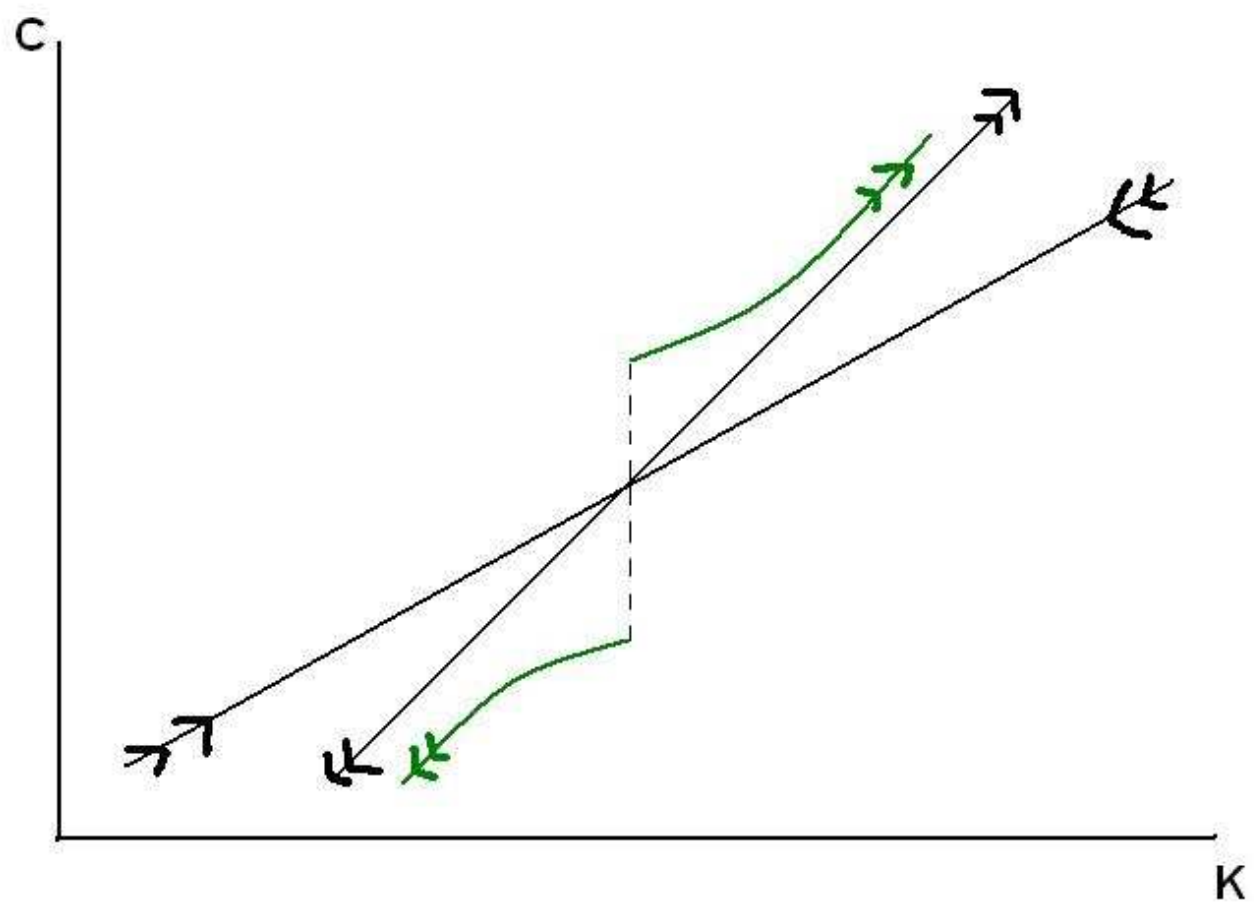

Figure 3: The Standard One-Sector Model

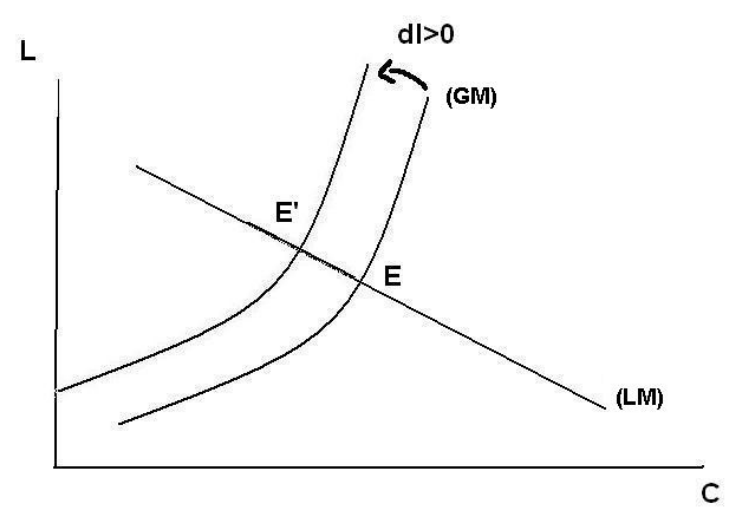


Figure 4: A Model with (enough) Increasing Returns $(\beta>\alpha)$

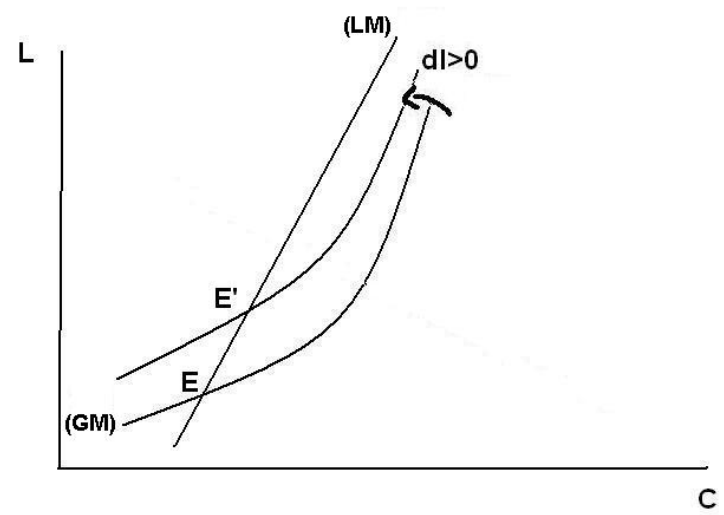

Figure 5: A Model with Sticky Prices

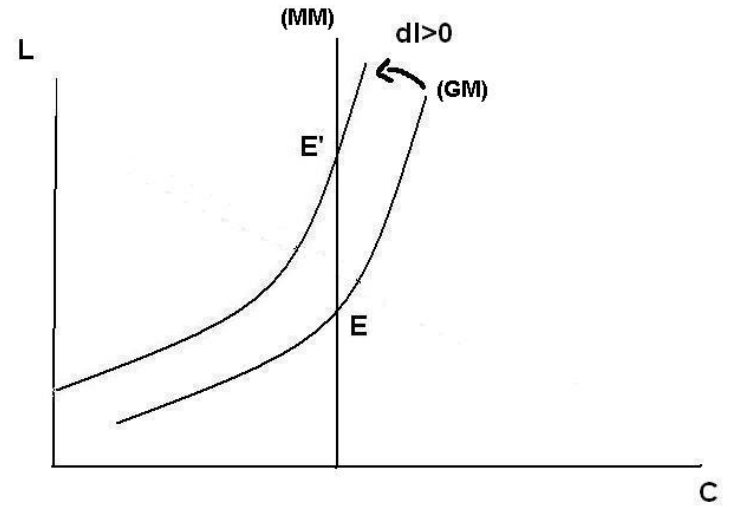


Figure 6: A Model with (large enough) Positive $G_{23}$

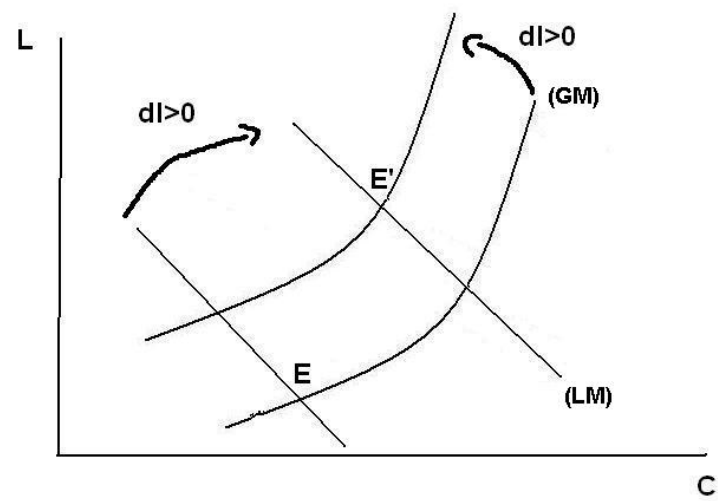


Figure 7: Response to a Tax Cut Surprise
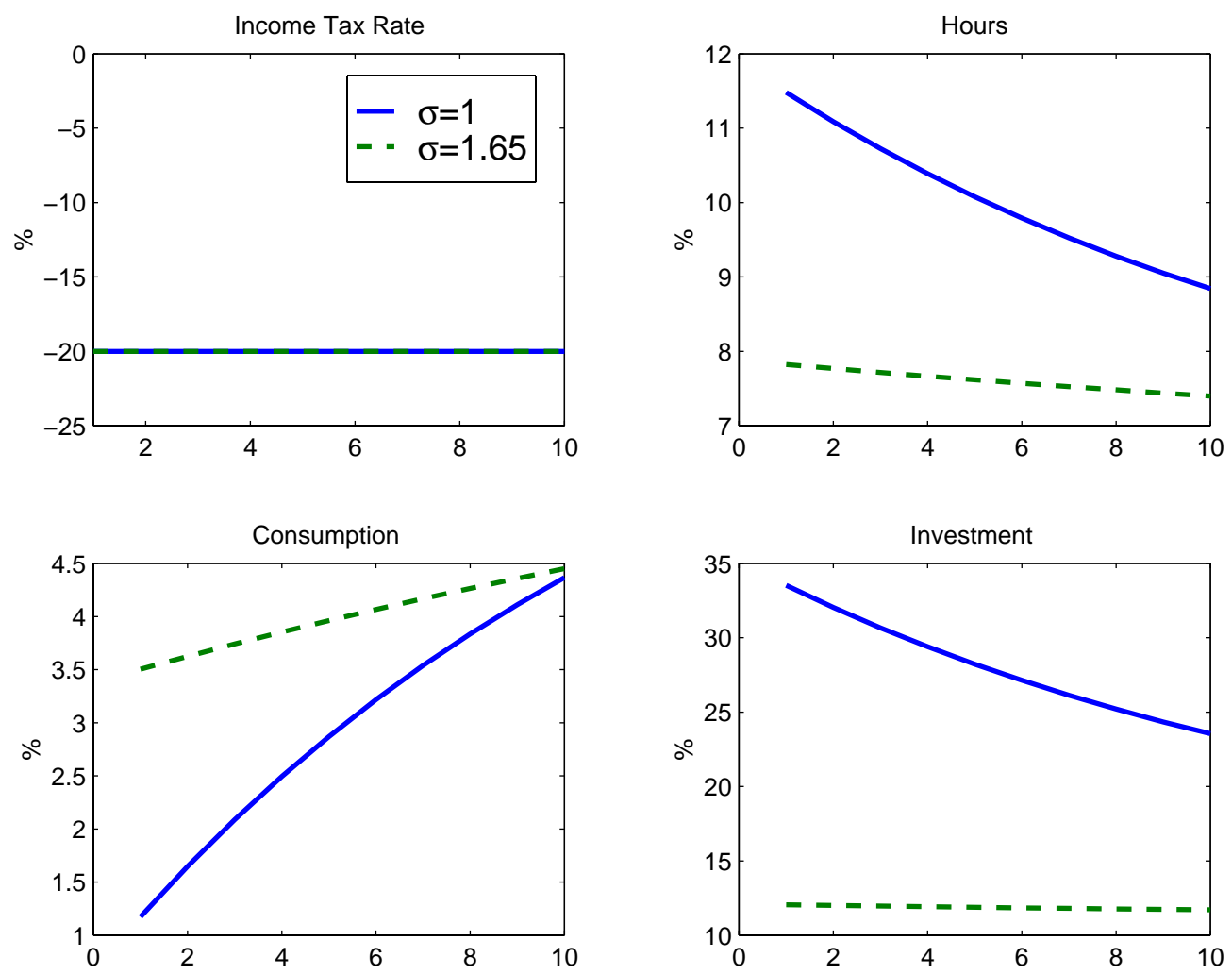

This figure shows the response of the tax rate, worked hours, consumption and investment to a permanent tax cut of 400 basis points. This tax cut is unexpected and implemented in period 1. All variables are expressed in percentage deviations from their initial steady state level. 
Figure 8: Response to a Tax Cut News
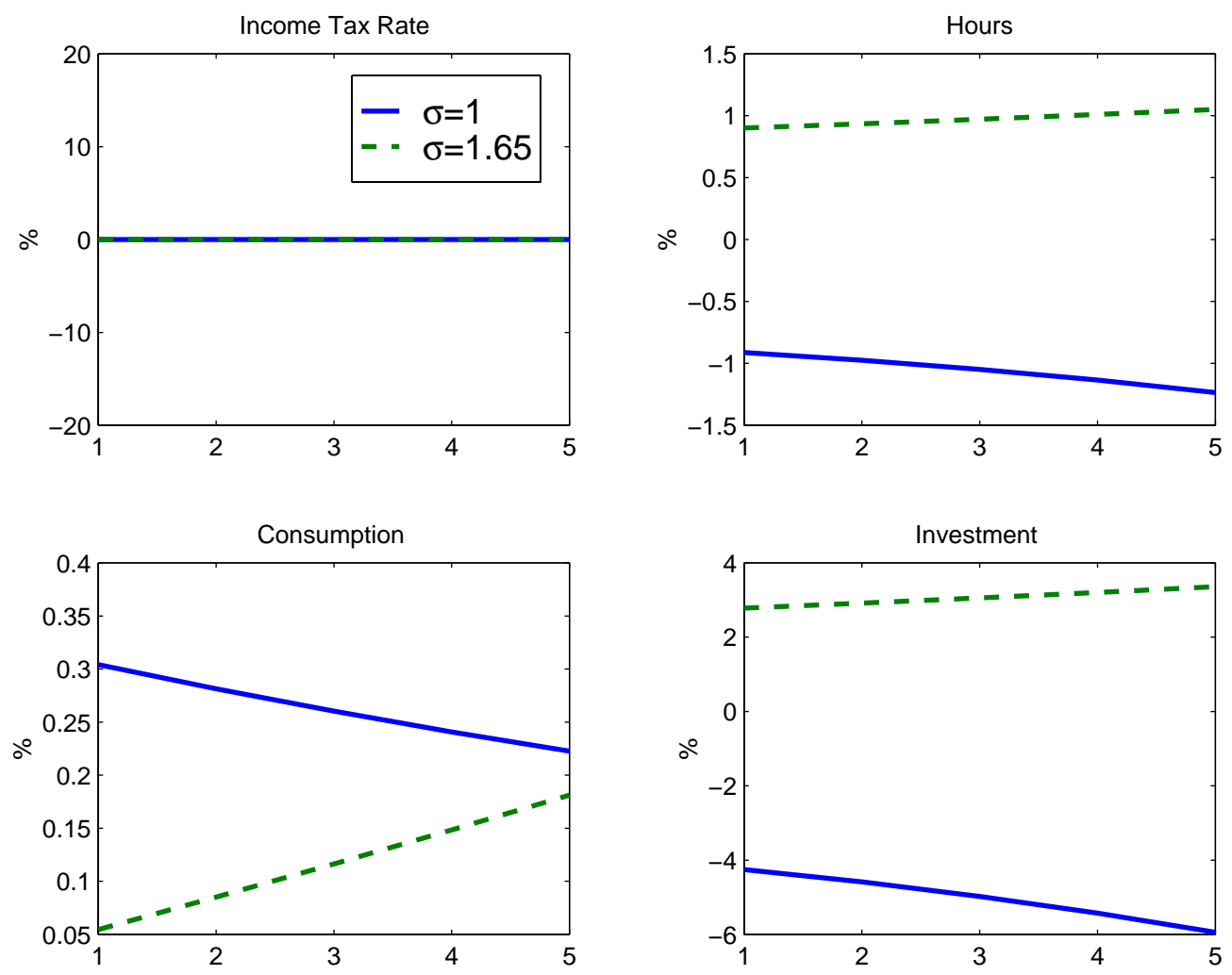

This figure shows the response of the tax rate, worked hours, consumption and investment to a permanent tax cut of 400 basis points. This tax cut is announced in period 1 and implemented in period 6. All variables are expressed in percentage deviations from their initial steady state level. 